\title{
Microstructural Characterization of Thermal Barrier Coatings Glazed by a High Power Laser
}

\author{
Hong Zhou ${ }^{1, a^{*}}$, Fei Li ${ }^{2, b}$, Jun Wang ${ }^{2, c}$, Bao-de Sun ${ }^{2, d}$ \\ ${ }^{1}$ Centre for Engineering and Industrial Design, Waikato Institute of Technology, \\ Hamilton 3240, New Zealand \\ ${ }^{2}$ State State Key Laboratory of Metal Matrix Composites, Shanghai Jiao Tong University, \\ Shanghai 200240, P. R. China \\ azhouhong.nz@gmail.com, blifei74@sjtu.edu.cn, junwang@sjtu.edu.cn, dbdsun@sjtu.edu.cn
}

Keywords: Surface laser-glazing, Thermal barrier coatings, Plasma Spray, Microstructure.

\begin{abstract}
Thermal barrier coatings have been widely used in in both energy and propulsion systems. Plasma-sprayed thermal barrier coatings have relatively high interconnected porosity and lamina structure, which bring out low bond strength, and lead to a short thermal cycling life. Lasers can be used for modification of materials surface. In this paper, plasma-sprayed thermal barrier coatings were laser-glazed by a high power laser in order to modify the structures. The microstructure of laser-glazed TBCs is investigated. The change on surface roughness has been examined. The result indicates that a smooth and dense glazed surface with craters and a network of microcracks is obtained after laser-glazing. The laser-glazed region consists of a columnar microstructure. There are segmentation microcracks in the laser-glazed coatings, which don't run through the coatings along thickness. Surface roughness has been reduced significantly for the laser treated ceramic coatings.
\end{abstract}

\section{Introduction}

The requirements for thermal barrier coatings (TBCs) in gas turbines are stringent due to extreme high temperatures and constant thermal cycling, which demands a material with excellent thermal shock resistance and thermal insulation properties. Plasma-sprayed duplex $\mathrm{ZrO}_{2}-8 \mathrm{wt} . \% \mathrm{Y}_{2} \mathrm{O}_{3} /$ MCrAlY ( $\mathrm{M}=\mathrm{Ni}$ and/or $\mathrm{Co}$ ) TBCs have been widely served in industrial gas turbine engines to provide thermal insulation, improve the efficiency and performance of metallic components at high temperatures [1-2]. Plasma-sprayed TBCs have relatively high interconnected porosity and lamina structure with splat boundaries and microcracks parallel to the interface, which are beneficial for low thermal conductivity. However, those microstructural features bring out a low bond strength of plasma-sprayed TBCs, lead to a short thermal cycling life.

Lasers have been used for modification of materials surface since lasers can deliver very high energy density to a localized surface area without significantly heating up the whole body. Laser-glazing leads to a quick remelting and subsequent rapid solidification of surface, which results in a dense top layer with new microstructure, reduced surface roughness and low porosity [3-4].

In this paper, plasma-sprayed thermal barrier coatings were investigated by laser-glazing with a high power laser in order to modify the structures. A study with focus on the microstructure of the laser-glazed TBCs is reported.

\section{Experimental Procedure}

Materials. Commercial available NiCrAlY metal powders (HHNiCrAlY-9, CAAMS, Beijing, China) with particle sizes ranging from 10 to $100 \mu \mathrm{m}$ were used for the bond coats. Commercial 8wt. $\%$ Yttria partially stabilized zirconia (YPSZ) powders (HHYPSZ, CAAMS, Beijing, China) with particle sizes from 38.5 to $63 \mu \mathrm{m}$, were selected for the ceramic coatings. NiCrAlY bond coats with thickness of about $0.1 \mathrm{~mm}$ were air plasma-sprayed onto the mild steel substrates before YPSZ coatings with thickness of about $0.3 \mathrm{~mm}$ were deposited on top of the bond coat by using the same air plasma spray system (DH80, CAAMS, Beijing, China). The spraying parameters are listed in Table 1. 
Table 1. The spraying parameters for the TBCs.

\begin{tabular}{cccccccc}
\hline & $\begin{array}{c}\text { Current } \\
{[\mathrm{A}]}\end{array}$ & $\begin{array}{c}\text { Voltage } \\
{[\mathrm{V}]}\end{array}$ & $\begin{array}{c}\text { Primary gas } \\
\mathrm{Ar}\left[1 \cdot \mathrm{min}^{-1}\right]\end{array}$ & $\begin{array}{c}\text { Primary gas } \\
\mathrm{N}_{2}\left[1 \cdot \mathrm{min}^{-1}\right]\end{array}$ & $\begin{array}{c}\text { Secondary gas } \\
\mathrm{H}_{2}\left[1 \cdot \mathrm{min}^{-1}\right]\end{array}$ & $\begin{array}{c}\text { Powder feeding } \\
\text { rate }\left[\mathrm{g} \cdot \mathrm{min}^{-1}\right]\end{array}$ & $\begin{array}{c}\text { Stand off } \\
\text { distance }[\mathrm{mm}]\end{array}$ \\
\hline NiCrAlY & 480 & 65 & 37 & - & 5 & 50 & 100 \\
YPSZ & 480 & 75 & - & 37 & $3-5$ & 15 & 60 \\
\hline
\end{tabular}

Methods. The Laser-glazing process was carried out on the plasma-sprayed TBC surface by using an industrial high power (maximum output power of $15 \mathrm{~kW}$ ) $\mathrm{CO}_{2}$ continuous wave laser (TLF15000, Trumph Lasercell, Germany) at a power of 3,500 W, as shown in Fig. 1. The laser system characteristics and processing parameters are listed in Table 2.

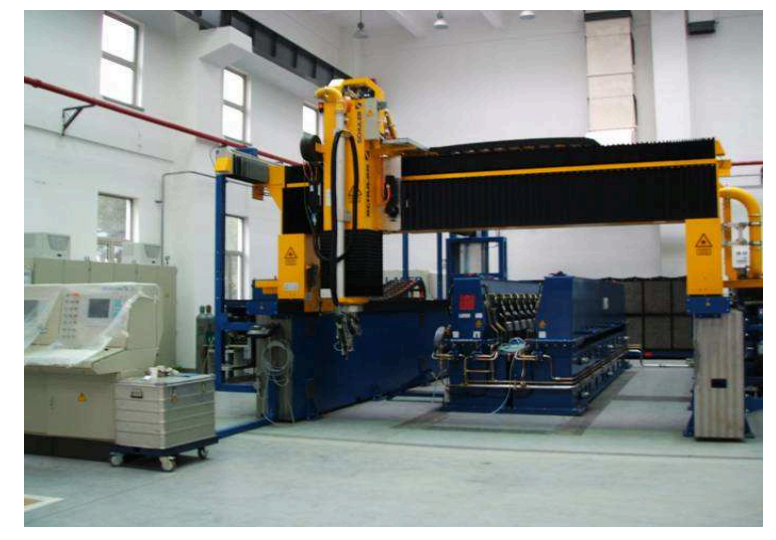

Fig. 1. The industrial $\mathrm{CO}_{2}$ continuous wave laser.
Table 2. Laser system characteristics and processing parameters.

\begin{tabular}{ll}
\hline Wave type: & Continuous \\
Wave length $(\mu \mathrm{m})$ & 10.6 \\
Raw beam size $(\mathrm{mm}):$ & 25 \\
Focal length $(\mathrm{mm}):$ & 357 \\
Focal point diameter $(\mathrm{mm}):$ & 0.7 \\
Defocus distance $(\mathrm{mm}):$ & 120 \\
Glazing beam diameter $(\mathrm{mm}):$ & 8.4 \\
Power $(\mathrm{W}):$ & 3,500 \\
Scanning speed $(\mathrm{mm} / \mathrm{min}):$ & 10000 \\
\hline
\end{tabular}

Microstructural characterization. Surface morphologies and coating microstructure were observed by using a field emission scanning electron microscope (FESEM, Model FEI Sirion 200, USA). Fractured and polished cross sections of the laser-glazed ceramic coatings, which were perpendicular to the laser beam travel, were prepared to determine morphological and microstructural modifications along the coating thickness. The arithmetic mean roughness $(R \alpha)$ of the ceramic coating surfaces with and without laser-glazing was determined by a mechanical profilometer (TR100, Time Inc., Beijing, China). The measurement is performed along two orthogonal directions on the coating surfaces. 10 measurements were taken for each sample, and the average value of all measurements was used as the arithmetic mean roughness $(\mathrm{R} \alpha)$ of the ceramic coating surfaces. The specifications for the surface roughness measurement are shown in Table 3.

Table 3. Specifications for the surface roughness measurement.

$\begin{array}{cc}\text { Tracing length, } \mathrm{mm} & 6 \\ \text { Cut off length, } \mathrm{mm} & 0.8 \\ \text { Tracing speed, } \mathrm{mm} / \mathrm{s} & 0.5\end{array}$

\section{Results and Discussion}

Microstructural Analyses. Fig. 2 depicts the surface morphology of the as-sprayed ceramic coating and the contrast of surface morphology in a region containing both laser treated and untreated areas. Thermal-sprayed coatings typically have a rough surface because they are formed by successive impingements and inter-bonding materials among splats, solidified individual molten particles. The surfaces of laser-glazed ceramic coatings have been changed apparently, which become much smoother, as shown in Fig. 2b. It is also observed from visual inspection that the laser-glazed surface turns into a light yellow glassy transparent color from the original pure white. There is no spallation found on the surface in any case. 
SEM observation in Fig. 3a shows that a network of microcracks, perpendicular to the densified surface, has been formed throughout the glazed surface of the ceramic coating. The microcracks are generated due mainly to thermal shock, shrinkage and thermal stresses induced by the fast cooling rate during the laser treatment. Batista et al. reported that low power laser-glazing with a small laser beam size on plasma-sprayed TBCs produced a network of microcracks with a tendency to be oriented in two perpendicular directions, one in the direction of the laser beam travel, the other vertical to it [5]. However, that phenomenon is not occurred in this case by using the high power laser. The microcrack networks at the surfaces of ceramic coatings are of irregular shape indeed.

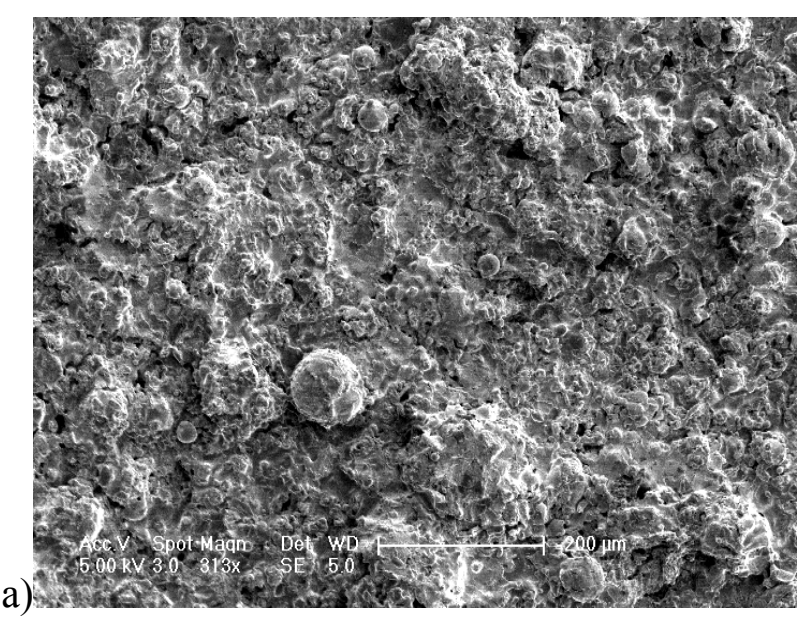

b)

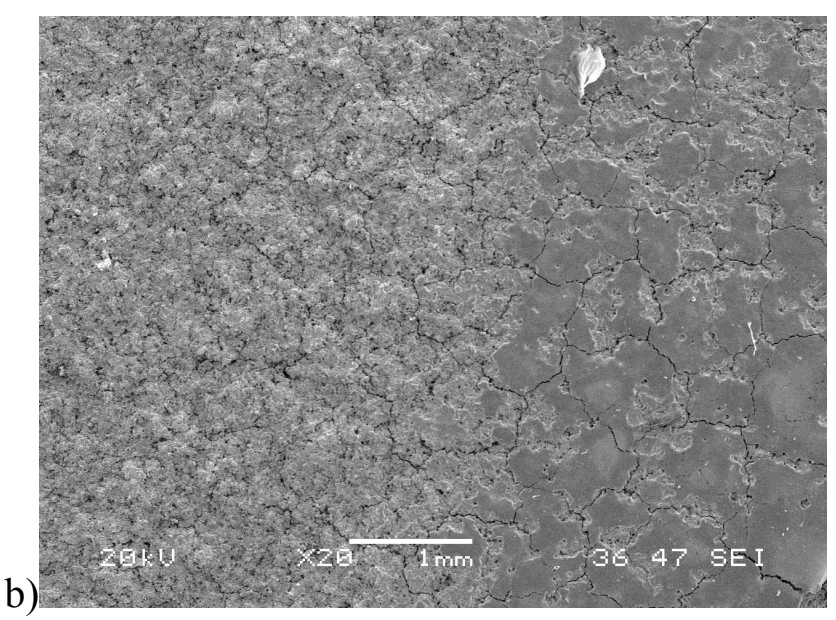

Fig. 2. SEM images of a) the top surface of the as-sprayed ceramic coating and $b$ ) the contrast of surface morphology in a region containing both laser treated (right) and untreated (left) areas.

Meanwhile, some craters appear on the laser-glazed ceramic surface, as illustrated in Fig. 3a. They are probably generated by the release of gas to surface at a region of the as-sprayed ceramic coatings with high porosity. The gas contained in the pores coalesce and rise to the surface during laser treatment, lead to the formation of surface craters when the ceramic solidification contains liquefaction. The amount of craters depends on the inherent amount of entrapped gas and the laser energy density. With the high power laser, there are more areas under the laser beam and this leads to more surface materials being melted during the laser scanning. Therefore, there are some craters produced on the laser-glazed coating surface.

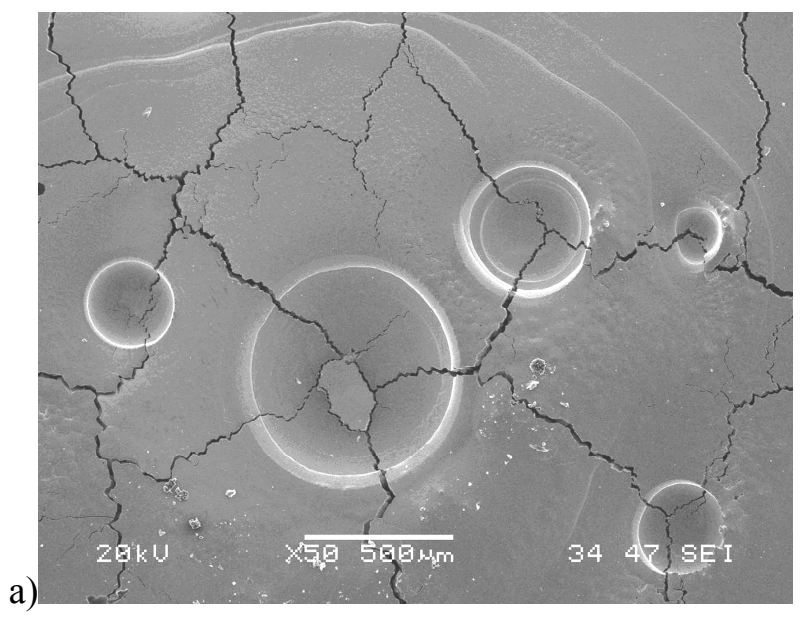

b)

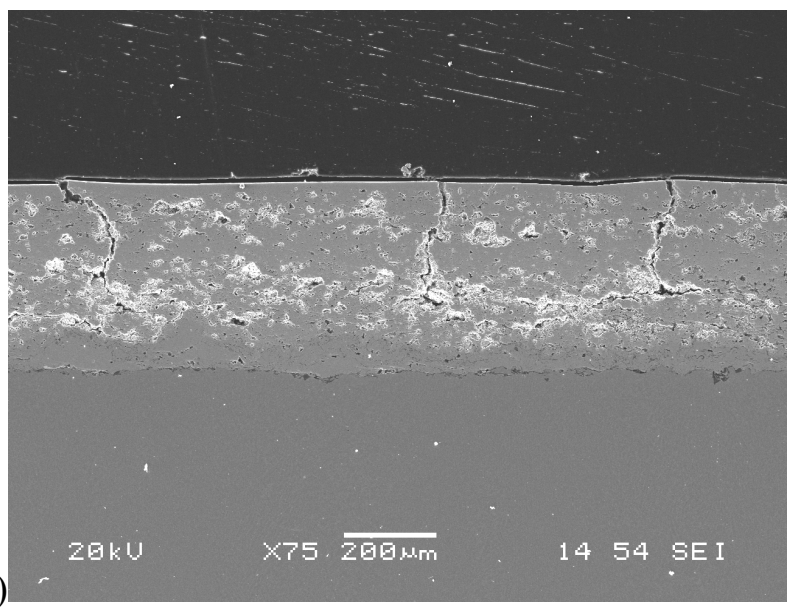

Fig. 3. a)The surface morphology and b) polished cross section of the laser-glazed TBCs.

Fig. $3 \mathrm{~b}$ presents the polished cross-section of laser-glazed TBCs. Segmentation microcracks along the densified layers have been observed in the ceramic coatings. All the segmentation microcracks don't go through the coatings along thickness, just end in the ceramic coatings. The segmentation microcrack is a characteristic feature of laser-glazed ceramic coatings and is generated by shrinkage 
and relaxation of thermal induced stresses of coating after laser-glazing. It is reported that a certain degree of segmentation microcracks is favorable in achieving a high level of thermal shock resistance for those microcracks could help accommodate the strains occurred during thermal cycling, and then improve the strain tolerance of coatings [6-7]. Since the laser-glazing process can produce segmentation microcracks within the ceramic layer, it is a promising method to improve the performance of plasma-sprayed TBCs.

The microstructure of laser-glazed top surface is shown in Fig. 4a. It presents a fine polygonal cell structure with grain sizes varied from 2-8 microns. Fig. $4 \mathrm{~b}$ shows the fractured cross section of coating. It reveals that the microstructure in the laser remelted regions is composed of columnar grains, which differe significantly from the lamina structure of plasma-sprayed coatings. Some small voids in the columnar grains can be observed. The release of gas during the laser remelting process, as discussed previously for the formation of craters on the coating surface, may be responsible for this phenomenon. The formation of columnar grains is a consequence of a unidirectional solidification of the liquid driven by a thermal gradient across the ceramic coatings. In the molten pool produced by laser irradiation, a thermal gradient which was perpendicular to the surface started to be formed immediately when the laser beam moved away from the molten pool. The heat was transmitted to the substrate and the surrounding air, then the grain growth was primarily perpendicular to the surface due to the direction of heat flow on cooling down to room temperature.
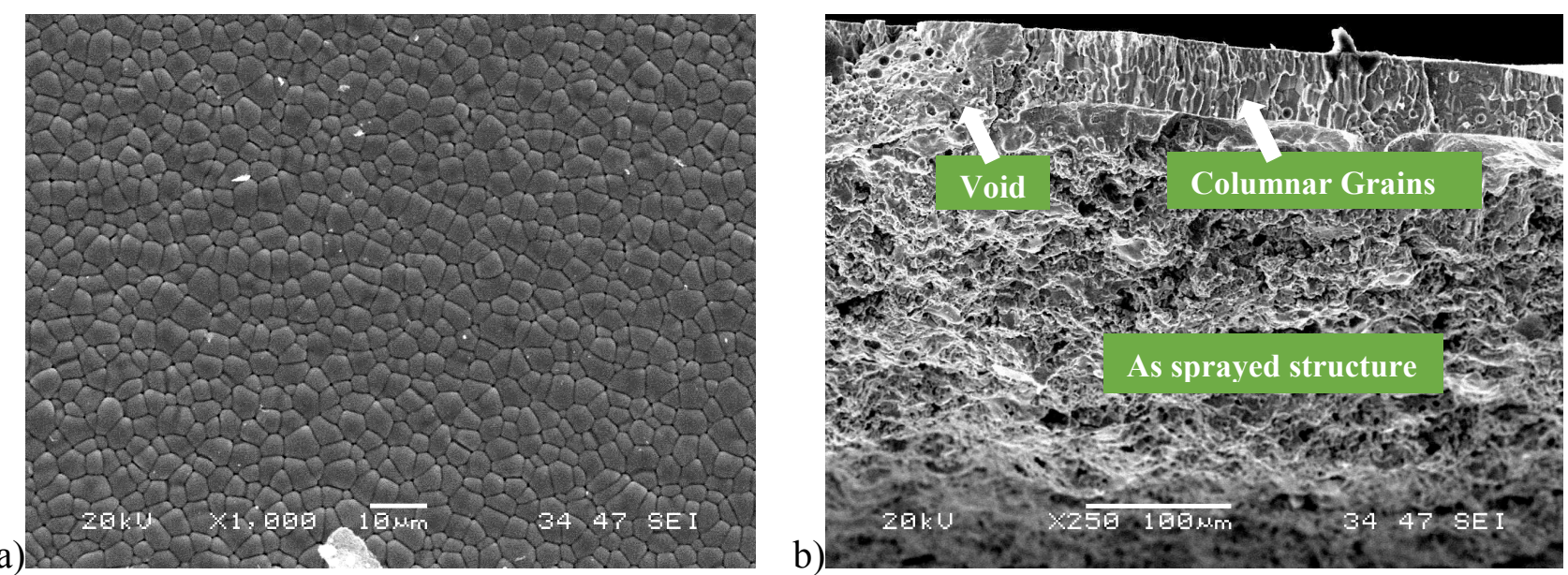

Fig.4. SEM images of a) the top surface and $b$ ) the fractured cross-section of the laser-glazed coatings.

Surface roughness. Surface roughness is a measurement of the irregularities in geometry of a surface. It influences not only microstructural characteristics and adhesion of a coating but also other coating properties such as friction coefficient, wear and corrosion resistance. Surface roughness $\left(R_{\alpha}\right)$ has been measured for the top ceramic coatings with and without laser-glazing. The surface roughness for as-sprayed coating is $9.3 \pm 0.8 \mu \mathrm{m}$, while that for the laser-glazed coating is reduced to $5.1 \pm 0.4 \mu \mathrm{m}$, as illustrated in Fig. 5. The result indicates an obvious reduction on surface roughness values after laser processing in spite of the forming of craters and microcrack networks on the surface, and thus generates a smoother surface.

Surface roughness usually results from the inherent action of material processing and/or the initial surface conditioning. As mentioned in the microstructural analyses section, coatings deposited by plasma spray processes have relatively rough surfaces mainly due to the build-up and interlocking of splat during the spray process. Meanwhile, the substrate has a rough surface which is necessary to promote adhesion of the coating to the substrate. This also partly contributes to a rough ceramic surface. When laser melting process is applied to melt the ceramic surface, high irregularities existed in the as-sprayed coatings are minimized. Thus, laser glazing process leads to achieving a homogeneous, consolidated, smooth and dense outer layer. 


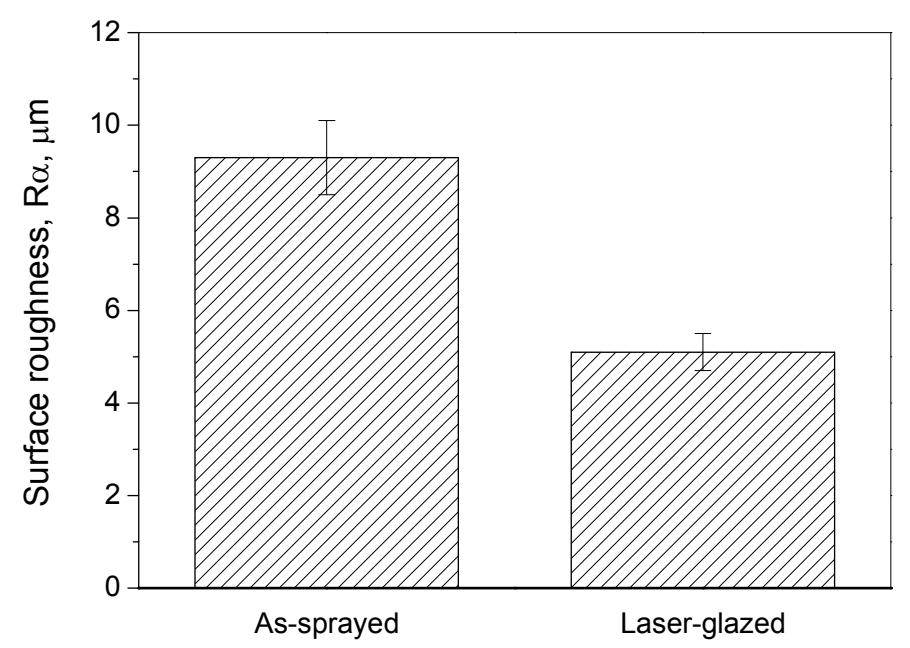

Fig. 5. Comparison of the surface roughness values $\left(R_{\alpha}\right)$ between the as-sprayed and the laser-glazed ceramic coatings.

\section{Conclusion}

Plasma-sprayed TBCs deposited with high interconnected porosity and lamina structure will bring out low bond strength, and lead to a short thermal cycling life. Laser treatment can modify materials properties because it provides a rapid remelting and subsequent solidification of the surface. Laser-glazing by a high power laser carried out on TBCs has resulted in a smooth and dense glazed surface with craters and a network of microcracks. The laser-glazed region consists of a columnar microstructure. The segmentation microcracks in the laser-glazed coatings have been observed, which don't run through the coatings along thickness. A significant change on surface roughness has been examined, and an obvious reduction on surface roughness is achieved after laser processing.

\section{References}

[1] N. P. Padture, M. Gell, E. H. Jordan, Thermal barrier coatings for gas-turbine engine application, Sci. 296 (2002) 280-286.

[2] H. Zhou, F. Li, J. Wang, B. Sun, Air plasma sprayed thermal barrier coatings on titanium alloy substrates, Surf. Coating Technol. 201(16-17) (2007) 7360-7367.

[3] C. Batista, A. Potrtinha, R. Rebeiro, Evaluation of laser-glazed plasma-sprayed thermal barrier coatings under high temperature exposure to molten salts, Surf. Coatings Technol. 200(24) (2006) 6783-6791.

[4] P. C. Tsai, C. S. Hsu, High temperature corrosion resistance and microstructural evaluation of laser-glazed plasma-sprayed zirconia/MCrAlY thermal barrier coatings, Surf. Coating Technol. 183(1) (2004) 29-34.

[5] C. Batista, A. Portinha, V. Teixera, M. F. Costa, C. Oliveira, R. M. Rebeiro, Surface laser-glazing of plasma-sprayed thermal barrier coatings, Appl. Surf. Sci. 247(1-4) (2005) 313-319.

[6] R. Mcpherson, A model for the thermal conductivity of plasma-sprayed ceramic coatings, A model for the thermal conductivity of plasma-sprayed ceramic coatingsThin Solid Film, 112(1) (1984) 89-95.

[7] H. Guo, S. Kuroda, H. Murakami, Segmented thermal barrier coatings produced by atmospheric plasma spraying hollow powders, Thin Solid Films, 506-507 (2006) 136-139. 